\title{
The Relationship of Serotonin to Depression in Parkinson's Disease
}

\author{
Richard Mayeux, Yaakov Stern, Mary Sano, Janet B. W. Williams, and \\ Lucien J. Cote
}

Departments of Neurology, Psychiatry, and Rehabilitation Medicine, College of Physicians and Surgeons, Columbia University, New York, New York, U.S.A.

\begin{abstract}
Summary: We have previously reported a correlation between depression in patients with idiopathic Parkinson's disease and decreased concentrations of the cerebrospinal fluid content of the serotonin metabolite, 5-HIAA. To further examine this relationship, we repeated the study in a new cohort of patients while they remained on dopaminergic medications, conducted follow-up interviews and examinations in our original cohort, and conducted an open trial of the serotonin precursor, 5-hydroxytryptophan in a group of new patients with depression. We were again able to demonstrate a significant reduction in cerebrospinal 5-HIAA in depressed patients in comparison to controls and patients without depression. Demented patients with Parkinson's disease, particularly those with concurrent depression, had the lowest values of 5-HIAA. No new cases of depression occurred in our original cohort after $2 \frac{1}{2}$ years of follow-up, and depression remitted following conventional or experimental treatment in four patients. Depression improved in six of the seven new patients following oral 5-hydroxytryptophan. Three of these patients allowed a repeat lumbar puncture, and the concentration of 5-HIAA increased following 5 -hydroxytryptophan. These three studies support our hypothesis that depression in idiopathic Parkinson's disease is associated with a reduction in brain serotonin. However, it also suggests that other factors, biological or environmental, may be causal factors. Key Words: Parkinson's diseaseSerotonin-5-Hydroxytryptophan.
\end{abstract}

\section{INTRODUCTION}

Depression is the most common mental disturbance in patients with Parkinson's disease (PD). Gotham et al. (1) reviewed 14 recent studies including over 1500 patients and estimated the mean prevalence to be $46 \%$, ranging from $20 \%$ to as high as $90 \%$ in various studies. In two earlier investigations $(2,3)$, we found one of

Address correspondence and reprint requests to Dr. R. Mayeux, Department of Neurology, Columbia University, Neurological Institute, 710 West 168th Street, New York, NY 10032. 
two types of depressive disorders in nearly half of the patients we investigated: major depression and dysthymic disorder. We have also found that $25 \%$ of depressed patients become depressed prior to the onset of the motor manifestations of PD (4).

The cause of depression in PD is unknown. Against a reactive depression is the lack of an association between depression and duration of illness, degree of disability, severity of parkinsonism, or response to medications (5). Others disagree, and consider depression to be related to the degree of disability and the severity of illness in PD because its prevalence is similar to that in patients with chronic illnesses, such as arthritis (1). We have observed a relationship between depression and reduced cerebrospinal fluid (CSF) levels of the metabolite of serotonin, 5-hydroxyindoleacetic acid (5-HIAA), during a dopamine agonist withdrawal period $(2,3)$. While this does not imply that depression is endogenous, it suggests that depression in patients with PD may be related to alterations in biogenic amines. A relationship between depression and serotonin has also been found in some depressed patients without PD $(6,7)$. This relationship between depression and reduced CSF 5-HIAA in PD suggests that reduced serotonin in brain may be related to the cause of depression.

To clarify the relationship between depression in PD and serotonin, we conducted three studies based upon our previous work:

(a) We measured the CSF content of 5-HIAA in patients with PD while they remained on dopamine agonists and related this information to clinical evidence of depression. This was a change from our previous methods in that we eliminated the drug withdrawal period prior to lumbar puncture in order to determine if the relationship would still exist under these more "natural" conditions.

(b) We conducted an open trial of oral L-5-hydroxytryptophan (L-5-HTP), the precursor to serotonin, in depressed patients with PD to examine its effect on mood.

(c) We also conducted follow-up interviews and examinations in previously studied parkinsonian patients to determine the incidence and natural history of depression.

\section{METHODS}

\section{Replication Study}

Forty-one consecutively encountered patients, from an outpatient urban hospital setting, considered to have idiopathic $\mathrm{PD}$, agreed to participate in the study protocol. No subject was selected because of the presence of a change in behavior or because of a particular type of behavioral disorder. However, it was difficult to avoid selection bias because patients had to volunteer to be hospitalized. After giving informed consent, all subjects entered a General Clinical Research Center (GCRC) for the psychiatric, neuropsychological, neurological, and CSFbiochemical studies to be described. Subjects remained on regular doses of dopamine agonists throughout the study; no patient was taking psychotropics or anticholinergics. 


\section{Psychiatric Diagnoses}

A structured psychiatric interview for diagnoses, according to the Diagnostic and Statistical Manual of Mental Disorders, third edition (DSM-III) (8). was conducted in every patient within $24 \mathrm{~h}$ of the lumbar puncture. We were particularly interested in the diagnosis of any depressive disorder or dementia, and used the Structured Clinical Interview for DSM-III (SCID) (9) to determine the presence or absence of relevant symptoms to establish whether diagnostic criteria were met.

\section{Neuropsychological Studies}

Each patient received a battery of neuropsychological tests measuring memory, language, attention, constructional ability, and general cognition. The diagnosis of dementia required all the criteria described in the DSM-III (8) for primary degenerative dementia; neuropsychological studies were used to confirm the diagnosis of dementia when it was suspected.

\section{CSF Studies}

A lumbar puncture for CSF studies was performed after $18 \mathrm{~h}$ bedrest. Twenty milliliters of CSF were removed for the biochemical studies, which were conducted using high pressure liquid chromatography with amperometric detection by a method we described earlier (10).

\section{L-5-HTP Trial}

Seven parkinsonian patients with major depression and low CSF 5-HIAA, defined as below $19.5 \mathrm{ng} / \mathrm{ml}$ of CSF from earlier investigations $(2,3)$, began an open trial of oral L-5-HTP. The initial daily dose was $75 \mathrm{mg}$; this was increased by 25 $\mathrm{mg} /$ day at intervals of about 3 days. Doses were increased until patients reported some reduction in depressive symptoms or to a maximal dose of $500 \mathrm{mg} / \mathrm{day}$. The final dosage was maintained for 4 months. In some patients carbidopa was added to prevent diarrhea and other unpleasant effects of 5-HTP. However, carbidopa was often taken in conjunction with levodopa and there was no need for more. The Hamilton Depression Rating Scale (HDRS) (11), Columbia University PD rating scale (12), and Schwab and England activities of daily living rating (ADL) (13) were performed prior to beginning the treatment and at monthly intervals during the open trial. Repeat lumbar punctures were performed in three of the seven patients who received oral 5-HTP; CSF 5-HIAA levels were repeated to assess any change that may have resulted from 5-HTP.

\section{Longitudinal Studies}

Forty-nine of 56 patients from our previous studies $(2,3)$ were reevaluated for depression and dementia. The mean duration between assessments was 2.5 years. A semi-structured interview was used to determine the presence or absence of depression or dementia. This examination included the HDRS score and the modified Mini-Mental State Examination (mMMS) (4). A family member or another informant was also interviewed if necessary. We were unable to examine 17 
patients personally, but sufficient information could be gathered by telephone from the patient's personal physician and family members regarding current clinical status to reach a diagnostic conclusion. Psychiatric diagnoses were derived from the interviews and we used the DSM-III criteria (8) as guides for the diagnosis of dementia and depression.

\section{RESULTS}

\section{Replication Study}

Of the 41 new subjects, there were 27 men and 14 women. Their mean age was 66.3 years (range $48-83$ years), mean years of education was 14.2 (range 5-19 years), and mean duration of illness was 7.6 years (range 2-30 years). Seven met criteria for major depression, 15 met criteria for primary degenerative dementia, and three met criteria for both. The remaining 16 patients were free of dementia or depression. A comparison of the CSF biogenic amine metabolites in these four groups is summarized in Table 1. There was a significant reduction in CSF 5HIAA in patients with major depression compared to those without depression or dementia $(F=3.22, p<0.05)$. Demented patients also had a reduction in CSF 5-HIAA, and their values did not differ significantly from the depressed or the nondepressed groups. Patients who were both demented and depressed had the greatest reduction in this metabolite but these values did not differ significantly from the depressed group. All patient groups differed from the comparison group composed of individuals that were neither depressed or demented. CSF- homovanillic acid (HVA) varied in the groups, but all patients were taking dopamine agonists precluding interpretation. The presence of depression or dementia did not relate to dosage of levodopa or CSF-HVA level. Corrected MHPG values did not differ between groups.

\section{L-5-HTP Trial}

Table 2 summarizes the results of this study. Improvement in depressive symptoms was noted in six of the seven patients who continued in the study as indicated by the reduction in the HDRS (11). One patient (patient no. 5) did not improve and eventually required electroconvulsive therapy. No significant change

TABLE 1. Biogenic amine metabolite values in four patient groups expressed in CSF $n g / m l$

\begin{tabular}{|c|c|c|c|c|}
\hline & $\begin{array}{l}\text { Not depressed or } \\
\text { demented }\end{array}$ & Demented & $\begin{array}{c}\text { Major } \\
\text { depression }\end{array}$ & $\begin{array}{l}\text { Depressed and } \\
\text { demented }\end{array}$ \\
\hline $\begin{array}{l}\text { N } \\
\text { Age } \\
\text { HVA } \\
\text { MHPG + } \\
\text { 5-HIAA }\end{array}$ & $\begin{array}{ll}16 & \\
59.8 \mathrm{a} & (7.7) \\
54.4 & (31.7) \\
3.9 & (1.9) \\
19.1 \mathrm{a} & (5.9)\end{array}$ & $\begin{array}{cc}15 & \\
75.2 \mathrm{~b} & (6.2) \\
52.1 & (31.4) \\
3.7 & (2.3) \\
15.5 \mathrm{ab} & (5.7)\end{array}$ & $\begin{array}{cc}7 & \\
64.0 \mathrm{a} & (4.4) \\
92.6 & (60.1) \\
3.9 & (2.9) \\
12.1 \mathrm{~b} & (6.7)\end{array}$ & $\begin{array}{cc}3 & \\
61.3 \mathrm{a} & (12.2)^{*} \\
52.1 & (31.6) \\
3.6 & (4.9) \\
10.9 \mathrm{~b} & (5.4)^{*}\end{array}$ \\
\hline
\end{tabular}

Values in parentheses are standard deviations, $p$ values are for ANOVA's comparing all group means for each variable. Means with the same letters do not differ significantly in post-hoc analyses.

* Differences were significant $\mathrm{p}<0.05$. + CSF-MHPG corrected as described previously (10). 
TABLE 2. S-HTP treatment in 7 parkinsonian patients with major depression

\begin{tabular}{|c|c|c|c|c|c|c|c|c|c|}
\hline \multirow{2}{*}{$\begin{array}{c}\text { Patient } \\
\text { No. }\end{array}$} & \multirow{2}{*}{$\begin{array}{l}\text { Levodopa } \\
\text { (mg/d) }\end{array}$} & \multirow{2}{*}{$\begin{array}{c}\text { Carbidopa } \\
\text { (mg/d) }\end{array}$} & \multirow{2}{*}{$\begin{array}{l}\text { 5-HTP } \\
\text { (mg/d) }\end{array}$} & \multicolumn{3}{|c|}{ Baseline } & \multicolumn{3}{|c|}{4 months 5-HTP } \\
\hline & & & & PDE & $\% A D L$ & HDRS & $\mathrm{PDE}$ & $\% A D L$ & HDRS \\
\hline 1. & 1000 & 175 & 125 & 49 & $80 \%$ & 22 & 41 & $80 \%$ & 11 \\
\hline 2. & 300 & 75 & 75 & 39 & $80 \%$ & 14 & 31 & $80 \%$ & 3 \\
\hline 3. & 400 & 150 & 100 & 38 & $65 \%$ & 21 & 37 & $70 \%$ & 13 \\
\hline 4. & 1000 & 100 & 100 & 67 & $60 \%$ & 12 & 43 & $85 \%$ & 6 \\
\hline 5. & 500 & 125 & 500 & 11 & $95 \%$ & 18 & 13 & $90 \%$ & 22 \\
\hline 6. & 1125 & 112.5 & 300 & 23 & $50 \%$ & 18 & 34.5 & $60 \%$ & 7 \\
\hline 7. & 500 & 50 & 100 & 11.5 & $95 \%$ & 17 & 5.5 & $95 \%$ & 13 \\
\hline
\end{tabular}

PDE, Parkinson's disease evaluation scale (13); \%ADL, percentage of independence in activities of daily living (12), and HDRS, Hamilton Depression Rating Scale (11).

in signs or symptoms of PD (12) was noted in any of the seven patients, and ADL scores (13) remained the same during the open 4 month trial.

CSF 5-HIAA increased in all three subjects who had repeat lumbar punctures (Table 3). In two of these subjects, CSF studies were repeated more than once; mood improved and 5-HIAA levels increased with higher dosages of 5-HTP. Parkinsonian signs and symptoms did not change significantly in these patients.

\section{Longitudinal Study}

Of the original 49 patients from earlier studies $(3,4), 13$ died. Postmortem examination was performed in five of these patients which confirmed the clinical diagnosis of PD in all five. Three of the five had coincident pathological features of Alzheimer's disease (AD) (14). None of the others allowed postmortem examination. Only one of the 49 patients could not be located. Among the 21 patients with either major depression or dysthymic disorder, four remitted (three with major depression and one with dysthymic disorder). In two patients, this remission was the result of standard treatment, and in another remission followed 5-HTP treatment. All three of the patients with major depression had CSF 5HIAA levels below $19.5 \mathrm{ng} / \mathrm{ml}$. The patient with dysthymic disorder improved without treatment.

No new cases of depression were encountered in any of the 28 other patients during the follow-up. This group included nine patients with low CSF levels of 5-HIAA and no evidence of depression at the time of the original studies $(2,3)$.

\section{DISCUSSION}

The replication component of this investigation, combined with our earlier studies $(2,3)$, strengthens the "serotonin hypothesis" for major depression in PD, and

TABLE 3. CSF 5-HIAA after 5-HTP administration

\begin{tabular}{cccccccc}
\hline & & & \multicolumn{2}{c}{ Baseline } & & \multicolumn{2}{c}{ After 5-HTP } \\
Patient & Age & Sex & $5-H I A A$ & HVA & & 5 -HIAA & HVA \\
\hline 1 & 69 & F & $9 \mathrm{mg} / \mathrm{ml}$ & $95 \mathrm{mg} / \mathrm{ml}$ & & $33 \mathrm{mg} / \mathrm{ml}$ & $71 \mathrm{mg} / \mathrm{ml}$ \\
2 & 48 & M & $10 \mathrm{mg} / \mathrm{ml}$ & $44 \mathrm{mg} / \mathrm{ml}$ & & $24 \mathrm{mg} / \mathrm{ml}$ & $82 \mathrm{mg} / \mathrm{ml}$ \\
3 & 55 & F & $25 \mathrm{mg} / \mathrm{ml}$ & $62 \mathrm{mg} / \mathrm{ml}$ & & $39 \mathrm{mg} / \mathrm{ml}$ & $122 \mathrm{mg} / \mathrm{ml}$ \\
\hline
\end{tabular}


suggests that the relationship can be detected when patients remain on dopamine agonists. However, two observations raise suspicion about its specificity. First, if lower concentrations of brain serotonin predispose to depression, we would have anticipated depression to develop in one of the nine nondepressed patients with low CSF 5-HIAA levels. The absence of new depression in the longitudinal study may simply reflect the small sample size. A larger cohort would be required to determine the incidence rate of depression in PD in general and would need to include patients with low CSF 5-HIAA as well. The absence of depression in the follow-up patients may simply indicate that the biochemical deficit is not the only prerequisite for depression, or that serotonin levels may not play a critical role in the chronicity of depressive disorders in PD.

Second, our finding of reduced CSF 5-HIAA levels in demented patients, particularly those with depression, was not anticipated. Postmortem investigations of $\mathrm{PD}$ and $\mathrm{AD}$ have indicated that the brain serotonin content may be reduced (15), and CSF 5-HIAA is reduced in patients with advanced AD (16). The cause of this reduction in $\mathrm{AD}$ and its clinical correlate are not established. Three of the demented patients (one with depression and dementia) from the follow-up cohort had pathological features of $A D$ and $P D$, and were reported earlier (14). Moreover, presynaptic markers for serotonin were reduced in all three patients (14). Subsequently, a patient with dementia and depression from the new study also had pathological features of AD on cortical biopsy, and reduced levels of CSF 5-HIAA.

Van Pragg and de Haan (7) consider reduced serotonin levels to increase the risk of depression because of the putative effect of serotonin on mood regulation. Serotonin levels are lower in the brains of elderly depressives who die of natural causes and suicide victims than in age-matched controls $(6,7)$. Stanley and associates (17) have found that imipramine binding, a presynaptic serotonin marker, is reduced in the frontal cortex of suicides, and Ninan et al. (18) reported that CSF 5-HIAA is lower in schizophrenics who attempt suicide than in those who do not (18). Thus, while depletion of brain serotonin may not directly cause depression, the relationship may implicate an important biochemical link to mood disorders in PD.

Dopamine does not appear to have a major role in depression; depression does not correlate with CSF-HVA. The elevated CSF-HVA levels in the current study probably reflect the administration of oral levodopa. Quantitative measures of disease severity or functional disability, and failure of levodopa to consistently alleviate depressive symptoms, also indicate the lack of an association between dopamine and depression. Traditional antidepressants improve depression, but have little effect on the motor manifestations of PD (5).

The open trial of 5-HTP in depressed patients with PD was encouraging and also supports a role for serotonin in depression. Prior to this study the dose range for treatment of depression in PD was not established, and the time-frame over which to expect drug effects was not clear. We did not treat severely depressed or suicidal patients because we were uncertain that 5-HTP would be effective. These patients have the lowest concentrations of CSF 5-HIAA and brain serotonin $(6,7)$. Previous studies of 5-HTP in PD were intended for motor manifestations; Chase 
et al. (19) found 5-HTP, in higher doses than we used, worsened PD but Sano and Taniguchi (20) found improvement. In nonparkinsonian depressed patients, only those with low CSF 5-HIAA concentrations respond favorably to 5-HTP treatment (21). Whether L-5-HTP is better than conventional antidepressants in PD remains to be determined. Our purpose was to examine the hypothesis which related depression to serotonin concentrations. The repeat CSF studies indicated an increase in CSF 5-HIAA levels when depression improved. A controlled investigation of this compound or a serotonergic antidepressant would seem an appropriate next step.

Follow-up of our previously examined patients showed that depression is relatively persistent, although it did resolve in four of the 21 patients. No new cases of depression were observed. While the incidence of depression in PD has not been investigated, the incidence of nonbipolar depression in people without PD has rarely been investigated. Boyd and Weissman (22) reviewed several studies and concluded that the lifetime risk for depression in the general population was $8-12 \%$ for men and $20-26 \%$ for women. The incidence of depression is $\sim 0.08-0.2 \%$ for men and $0.2-0.6 \%$ for women. The incidence increases with negative life events, and is higher in medically ill patients and the elderly $(22,23)$. We would have expected depression to be more frequent in the follow-up of our patients, but the small number of patients with low CSF 5-HIAA may have precluded a reasonable study of incidence.

Sampling and assessment techniques account for much of the variation in studies of the prevalence of depression in PD. Diagnosis based on depression scales is not always accurate because these scales assess the presence of symptoms of depression, not the presence of criteria for diagnosis. Self-reporting scales are also difficult to interpret because many of the items confound manifestations of depression and PD. However, when a criterion based interview is used, the HDRS score (11) usually reflects the severity of depression. Although the prevalence of depression in PD is greater than that expected for healthy persons (5), the prevalence in comparison to other equally disabling illnesses is still the subject of controversy (1).

In the current study, we have added further evidence for our hypothesis that depression in patients with PD is related to a reduction in brain serotonin. The relationship may be present in demented patients with PD who are also depressed. While interesting, this observation needs to be confirmed by others. Our study does not distinguish between a reactive or primary depression in PD. Nevertheless, there is clearly a biochemical correlate that may allow for the development of a rational treatment for this behavioral problem.

\section{ADDENDUM}

After the submission of our paper we encountered the work of Kostic et al. (Kostic VS, Djuricic BM, Covickovic-Sternic N, Bumbasirevic L, Nikolic M, Mrsulja BB. Depression and Parkinson's disease: possible role of serotonergic mechanisms. $J$ Neurol 1987;234:94-6). They essentially replicated our study in a cohort of 26 patients with Parkinson's disease. The levels of CSF-5-HIAA were 
significantly lower in the depressed parkinsonian group than in the nondepressed group or in the control population. There was no relationship between the severity of motor manifestations of Parkinson's disease and depression. This is the first study, to our knowledge, replicating our previous investigation.

Acknowledgments: The authors with to express their appreciation to the nursing and supporting staff of the General Clinical Research Center of the Columbia Presbyterian Medical Center. This work was supported in part by Health Services Grants AG-02802 and the Parkinson's Disease Foundation. It was completed in a federally supported General Clinical Research Center and data were stored and analysed on CLINFO (RR00645).

\section{REFERENCES}

1. Gotham AM, Brown RG, Marsden CD. Depression in Parkinson's disease: a quantitative and qualitative analysis. $J$ Neurol Neurosurg Psychiatry 1986;49:381-9.

2. Mayeux R, Stern Y, Cote L, Williams JBW. Altered serotonin metabolism in depressed patients with Parkinson's disease. Neurology 1984;34:642-6.

3. Mayeux R, Stern Y, Williams JBW. Clinical and biochemical features of depression in Parkinson's disease. Am J Psychiatry 1986;143:756-9.

4. Mayeux R, Stern Y, Rosen J, Leventhal J. Depression, intellectual impairment, and Parkinson's disease. Neurology 1981;31:645-50.

5. Mayeux R. Depression and dementia in Parkinson's disease. In: Marsden CD, Fahn S, eds. Movement Disorders. London: Butterworth 1982:75-95.

6. van Praag HM. Depression. Lancet 1982;2:1259-64.

7. van Praag HM, de Haan S. Central serotonin metabolism and frequency of depression. Psychiatry Res 1979;1:219-24.

8. American Psychiatric Association. Diagnostic and statistical manual of mental disorders, 3 rd ed. Washington, D.C.: APA, 1980:205-24.

9. Robbins CN, Helzer JE, Ratcliff KS, Segfred W. Validity of diagnostic interview schedule, version II: DSM III diagnoses. Psychol Med 1982;56:855-8.

10. Mayeux R, Stern Y, Sano M, Cote L. Bradyphrenia in Parkinson's disease: clinical features and biochemistry. Neurology 1987;37:1130-4.

11. Hamilton M. A rating scale for depression. I Neurol Neurosurg Psychiatry 1960;23:56-62.

12. Lesser RP, Fahn S, Snider SR, Cote LJ, Isgreen WP, Barrett RE. Analysis of the clinical problems in parkinsonism and the complications of long-term levodopa therapy. Neurology 1979;29:1253-60.

13. Schwab JF, England AC. Projection technique for evaluating surgery in parkinson's disease. In: Gillingham FJ, Donaldson, eds. Third symposium on Parkinson's disease. Edinburgh: Livingston, 1969:152-7.

14. D'Amato RA, Zweig RM, Whitehouse PJ, et al. Aminergic systems in Alzheimer's disease and Parkinson's disease. Ann Neurol 1987;22:229-36.

15. Schimiya Y, Arai H, Kosaka K, lazutea R. Morphological and biochemical changes in the cholinergic and monoaminergic systems in Alzheimer-type dementia. Acta Neuropathol (Berl) $1986 ; 70: 112-6$.

16. Soininen H, MacDonald E, Retionene M. Homovanillic acid and 5-hydroxyindoleacetic acid levels in cerebrospinal fluid of patients with senile dementia of Alzheimer type. Acta Neurol Scand $1981 ; 64: 101-7$.

17. Stanley M, Virgilio J, Gershon S. Tritiated imipramine binding sites are decreased in the frontal cortex of suicides. Science 1982;216:1337-9.

18. Ninan PT, van Kammen DT, Schenin M. SF 5-hydroxyindolacetic acid levels in suicide schizophrenic patients. Am J Psychiatry 1984;141:566-72.

19. Chase TN, Ng LKY, August M. Parkinson's disease: modification by L-5-hydroxytryptophan. Neurology 1972;22:479-84.

20. Sano VI, Taniguchi K. L-5-hydroxytryptophan (L-5-HTP) Therapie des morbus Parkinson. MMWR 1972;114:1717-9.

21. van Praag H. Serotonin precursors in the treatment of depression. In: Serotonin in biological psychiatry. Ho BT, Schoolar JC, Usdin E, eds. New York: Raven Press, 1982:259-86.

22. Boyd JH, Weissman M. Epidemiology of affective disorders. Arch Gen Psychiatry 1981;38:1039 46.

23. Rodin G, Voshart K. Depression in the medically ill: an overview. Am J Psychiatry 1986;143:695705 . 